\title{
Effects of Oxygen Supply During Training on Subjects With COPD Who Are Normoxemic at Rest and During Exercise: A Blinded Randomized Controlled Trial
}

\author{
Marc Spielmanns MD, Chantal Fuchs-Bergsma MD, Aurelia Winkler MD, Gabriele Fox MD, \\ Stefan Krüger MD, and Klaus Baum PhD
}

\begin{abstract}
BACKGROUND: It is well established that physical training enhances functionality and quality of life in patients with COPD. However, little data exist concerning the effects of the usefulness of oxygen supply during exercise training for $>3$ months in patients with COPD who are normoxemic at rest and during exercise. We hypothesized that oxygen supply during training sessions enables higher training intensity and thus optimizes training results in patients with COPD. METHODS: In this blinded randomized controlled study, we carried out a 24 -week training program with progressively increasing loads involving large muscle groups. In addition, we compared the influences of oxygen supplementation. Thirty-six subjects with moderate-to-severe COPD who were not dependent on long-term oxygen therapy trained under supervision for 24 weeks ( 3 times/week at $30 \mathrm{~min} / \mathrm{session})$. Subjects were randomized into 2 groups: oxygen supply via nasal cannula at a flow of $4 \mathrm{~L} / \mathrm{min}$ and compressed air at the same flow throughout the training program. Lung function tests at rest (inspiratory vital capacity, $\mathrm{FEV}_{1}$, Tiffeneau index), cycle spiroergometry (peak ventilation, peak oxygen uptake, peak respiratory exchange rate, submaximal and peak lactic acid concentrations), 6-min walk tests, and quality-of-life assessments (Medical Outcomes Study 36-Item Short Form questionnaire) were conducted before and after 12 and 24 weeks. RESULTS: Independent of oxygen supplementation, statistically significant improvements occurred in quality of life, maximal tolerated load during cycling, peak oxygen uptake, and 6-min walk test after 12 weeks of training. Notably, there were no further improvements from 12 to 24 weeks despite progressively increased training loads. CONCLUSIONS: Endurance training 3 times/week resulted in significant improvements in quality of life and exercise capacity in subjects with moderate-to-severe COPD within the initial 12 weeks, followed by a stable period over the following 12 weeks with no further benefits of supplemental oxygen. Key words: COPD; pulmonary rehabilitation; interval; constant load; training; oxygen supply; exercise training [Respir Care 2015;60(4):540-548. (C) 2015 Daedalus Enterprises]
\end{abstract}

Introduction

One of the main symptoms of COPD is dyspnea caused by air-flow limitation; therefore, patients with COPD tend

\footnotetext{
Drs Spielmanns, Fuchs-Bergsma, Winkler, and Fox are affiliated with the Department of Internal Medicine, St Remigius Hospital, Leverkusen, Germany. Dr Krüger is affiliated with the Department of Pneumology, Allergology, Sleep and Respiratory Medicine, Kaiserswerther Diakonie, Düsseldorf, Germany. Dr Baum is affiliated with Trainingsinstitut Prof Dr Baum, Cologne, Germany. Dr Spielmanns is also affiliated with the Faculty of Health, School of Medicine, Witten/Herdecke University, Witten/Herdecke, Germany.
}

to abstain from strenuous physical activities. ${ }^{1}$ As a consequence, a marked reduction in strength and endurance of

\footnotetext{
This study was supported by VitalAire. The authors have disclosed no conflicts of interest.

Dr Spielmanns presented a version of this paper at the Best in Pulmonary Rehabilitation of the Annual Meeting of the German Respiratory Society, held March 26-29, 2014, in Bremen, Germany.

Correspondence: Marc Spielmanns MD, Department of Internal and Pulmonary Medicine, St Remigius Hospital, An St Remigius 26, 51379 Leverkusen, Germany. E-mail: spielmanns@k-plus.de.
}

DOI: $10.4187 /$ respcare. 03647 
peripheral skeletal muscles has been reported. ${ }^{2}$ Besides a lack of exercise stimuli, muscle wasting may also originate from systemic inflammation ${ }^{3}$ and corticosteroid therapy. ${ }^{4}$ COPD is characterized by a pronounced exercise intolerance that occurs at an early stage of the disease. ${ }^{5}$ There is strong evidence that COPD-induced exercise intolerance can be counteracted in part by regular physical activities. COPD guidelines recommend physical exercises as a substantial non-pharmacologic part of the therapeutic strategy. ${ }^{6}$ According to the current guidelines, the beneficial effects of pulmonary rehabilitation and physical activity cannot be overstated. ${ }^{7}$ The question arises as to what level patients with COPD are able to further enhance their performance capacity when the training period is expanded. Therefore, one outcome of this study was the comparison of changes in endurance parameters and quality of life within a supervised long-term training intervention lasting 24 weeks with an interim analysis after 12 weeks. The equivalence of physiologic benefits between continuous and interval training is well known in the literature. ${ }^{8}$ Therefore, the training program was a mixture of continuous and interval training. However, the potential benefit of oxygen supplementation during exercise is still a matter of debate. Nevertheless, several studies have shown the positive effect of oxygen supply during exercise training in patients with COPD. ${ }^{9,10}$ We hypothesized that normoxemic subjects with COPD undergoing exercise training while breathing supplemental oxygen would reach a higher intensity and therefore improve in exercise capacity compared with subjects breathing air.

\section{Methods}

\section{Subjects}

This blinded randomized controlled study was conducted consecutively with 85 subjects with COPD. They were invited to take part when referred by general practitioners to the St Remigius Hospital in Leverkusen, Germany, from September 2009 to March 2011. The final evaluations were finished in September 2011. Subjects were educated in detail about study objectives, and written informed consent was obtained. Pre-training tests were performed, and training started individually within the next week. Workouts were carried out at the Trainingsinstitut Prof Dr Baum in Cologne. A criterion for fulfilling the training was participation in at least $80 \%$ of the sessions. Subjects were randomly allocated to one of 2 groups (see below). The randomization scheme was generated using the website Randomization.com (http://www.randomization.com) using a computer-generated list of random numbers to assign subjects to either the oxygen or compressed air group. The study was approved by the ethics committee of the German Sport University Cologne in Germany and

\section{QUICK LOOK}

\section{Current knowledge}

Pulmonary rehabilitation is a comprehensive intervention that promotes improvements in exercise capacity, symptoms, and quality of life in patients with clinical and functional pulmonary impairment. The duration of exercise training required to impact a change is variable, and the role of oxygen supplementation during exercise is not defined.

\section{What this paper contributes to our knowledge}

Cycle training increased exercise performance and quality of life to comparable amounts after 12 weeks of structured physical training. Exercise performance reached a ceiling effect after 12 weeks. There was no influence of oxygen supplementation during exercise in normoxemic subjects with COPD.

registered at the German Clinical Trials Register (DRKS, www.drks.de) under registration DRKS00006077. Only subjects with a diagnosis of COPD and $\mathrm{FEV}_{1} / \mathrm{FVC}$ of $<0.7$ after bronchodilation with $\mathrm{FEV}_{1}$ of $<80 \%$ of predicted were included. A stable clinical condition for at least 4 weeks and normoxemia at rest and during exercise without oxygen supply $\left(\mathrm{S}_{\mathrm{pO}_{2}}\right.$ of $\left.>90 \%\right)$ qualified subjects for inclusion. Subjects were instructed to avoid performing individual regular physical training until the study started. Exclusion criteria were other diseases that could interfere with training (eg, ischemic cardiac disease, muscularskeletal problems), desaturation during exercise of $<90 \%$, and psychological disorders.

\section{Assessments}

Measurements were obtained following randomization at the beginning of the study (baseline), after 12 weeks, and within 1 week after the 24 weeks of training. Exercise tolerance was measured by the 6-min walk test (6MWT) and cycle spiroergometry. The 6-min walk distance was the primary outcome measurement, whereas maximum work load, maximum oxygen uptake $\left(\dot{\mathrm{V}}_{\mathrm{O}_{2}}\right)$, and Medical Outcomes Study 36-Item Short Form questionnaire (SF-36) results were secondary outcomes. Exercise tests (6MWT and spiroergometry) were performed without any oxygen supply.

6MWT. Subjects were encouraged to walk at their own maximal speed (but without running) back and forth $(30 \mathrm{~m})$ according to the American Thoracic Society guidelines for the performance of a $6 \mathrm{MWT} .{ }^{11}$ To prevent bias from the testing supervisor, no encouragement was given. Subjects 


\section{$\mathrm{O}_{2}$ Supply During Exercise Training in Subjects With COPD}

were allowed to rest, but they could restart again within the allocated 6 min.

Spiroergometry. Spiroergometry was performed on a cycle ergometer (Emotion Cycle 400, Ergoline, Bitz, Germany) with subjects sitting in an upright position. Subjects breathed room air through a mask connected to flow and gas sensors (ZAN 680 spirometry system, nSpire Health, Oberthulba, Germany). Ventilation and inspiratory and expiratory $\mathrm{P}_{\mathrm{O}_{2}}$ and $\mathrm{P}_{\mathrm{CO}_{2}}$ were monitored continuously, and peak ventilation, peak $\dot{\mathrm{V}}_{\mathrm{O}_{2}}$, and peak $\mathrm{CO}_{2}$ release were calculated offline for the last $30 \mathrm{~s}$ before exhaustion. Heart rate was recorded by electrocardiogram leads via chest electrodes. After $3 \mathrm{~min}$ of rest, exercise started at $25 \mathrm{~W}$ and was automatically increased to $10 \mathrm{~W}$ every 3 min until subjective exhaustion. ${ }^{12}$ Lactic acid concentration was determined at rest and at the end of each work load by means of arterialized blood taken from an ear lobe (Accutrend lactate analyzer, Roche Diagnostics, Mannheim, Germany). ${ }^{13,14}$ All exercise testing (spiroergometry and 6MWT) was performed in the afternoon.

Training Cycle Tests. Tests were conducted with the same work load protocol as for spiroergometry. One group was supplied with $4 \mathrm{~L} / \mathrm{min}$ oxygen via a nasal cannula (oxygen group). An oxygen supply of $4 \mathrm{~L} / \mathrm{min}$ was chosen to increase the oxygen content of the inhaled air from $21 \%$ to $\sim 35 \%$, according to our previous study, where we used $40 \%$ oxygen. ${ }^{9}$ Another group received compressed air at the same flow via a nasal cannula (compressed air group). Lactic acid concentration was determined as described above, and heart rate was monitored with a heart rate monitor (FT60, Polar Electro, Lake Success, New York). Tests were conducted by an unblinded coach; the subjects and investigator were not aware of the group to which they belonged until the end of all experiments.

Subjective Parameters. Quality of life was assessed using SF-36. ${ }^{15}$ This questionnaire includes the subgroups vitality, bodily pain, general health, mental health, physical functioning, physical role functioning, emotional role functioning, and social functioning. All scores range from 0 (worst condition) to 100 (best condition).

Training. All training sessions were individually conducted on the same ergometer and supervised by professional staff. All sessions lasted $30 \mathrm{~min}$ and were conducted 3 times/week. Both groups started with 12-week interval training followed by an additional 12 weeks of continuous training. Training intensity was assessed according to the baseline and 12-week training cycle tests and progressively increased every 3 weeks (Table 1). The total amount of work was identical in the continuous and interval training modes within a given period. The preference for con-
Table 1. Duration and Intensity of Training Session

\begin{tabular}{lcc}
\hline \hline \multirow{2}{*}{ Weeks } & \multicolumn{2}{c}{ Duration and Intensity (Maximum Work Load) } \\
\cline { 2 - 3 } & Continuous Load & Interval Load \\
\hline $1-3,13-15$ & $30 \mathrm{~min}, 70 \%$ & $6 \times(4 \mathrm{~min}, 60 \%+1 \mathrm{~min}, 110 \%)$ \\
$4-6,16-18$ & $30 \mathrm{~min}, 75 \%$ & $6 \times(4 \mathrm{~min}, 65 \%+1 \mathrm{~min}, 115 \%)$ \\
$7-9,19-21$ & $30 \mathrm{~min}, 80 \%$ & $6 \times(4 \mathrm{~min}, 70 \%+1 \mathrm{~min}, 120 \%)$ \\
$10-12,22-24$ & $30 \mathrm{~min}, 85 \%$ & $6 \times(4 \mathrm{~min}, 75 \%+1 \mathrm{~min}, 125 \%)$ \\
\hline
\end{tabular}

Intensity was adjusted according to the results before (weeks 1-12) and after (weeks 13-24) 12 weeks of training.

tinuous or interval training was indicated in a questionnaire in the post-training (after 24 weeks) evaluation.

\section{Statistical Analysis}

Sample size was calculated using the 6MWT before and after treatment as the primary outcome variable. Assumptions were based on the results of the only previous study performed in a similar population (double-blinded controlled study ${ }^{9}$ ). Considering a mean improvement in the 6-min walk distance of $55 \mathrm{~m}$ with an SD of $90 \mathrm{~m}$, a significance level of .05 , and a power of $80 \%$ after treatment, there were 42 subjects included in each study arm. Data were analyzed using SPSS (SPSS, Chicago, Illinois). Continuous variables are presented as mean $\pm \mathrm{SD}$, and categorical data are presented as a percentage. For comparative analysis, a 2-way analysis of variance was performed with the variables time, oxygen supply, and training mode. In the case of significant effects, Bonferroni post hoc analysis was done for detailed information. The limit of significance was set to $P<.05$.

\section{Results}

Nineteen subjects in the oxygen group and 17 subjects in the compressed air group completed the study. There were no baseline differences between the groups (Table 2). Thirty-nine subjects did not complete the 12-week training intervention. During the 24-week follow-up, 10 subjects discontinued the study (Fig. 1). Eleven subjects did not complete the training intervention for health reasons (mainly surgical interventions), 11 subjects because training was too extensive, 5 subjects for personal reasons (mainly training was too strenuous), 5 subjects sent no feedback, and 7 subjects due to exacerbations. No differences in age, COPD stage, and group (oxygen supply or air supply) were found between dropouts and other subjects.

\section{Lung Function}

Table 3 shows lung function parameters at baseline and after 12 and 24 weeks of training. No significant change in 
Table 2. Subject Characteristics at Baseline

\begin{tabular}{|c|c|c|}
\hline Characteristic & $\begin{array}{l}\text { Compressed } \\
\text { Air Group } \\
(n=17)\end{array}$ & $\begin{array}{c}\text { Oxygen Group } \\
(n=19)\end{array}$ \\
\hline Age $($ mean $\pm \mathrm{SD}), \mathrm{y}$ & $64 \pm 8.4$ & $65 \pm 8.7$ \\
\hline Height (mean $\pm \mathrm{SD}), \mathrm{m}$ & $1.7 \pm 0.1$ & $1.7 \pm 0.1$ \\
\hline Weight (mean $\pm \mathrm{SD}), \mathrm{kg}$ & $75 \pm 15.7$ & $69 \pm 12.2$ \\
\hline $\mathrm{BMI}($ mean $\pm \mathrm{SD}), \mathrm{kg} / \mathrm{m}^{2}$ & $26 \pm 4.7$ & $24 \pm 3.2$ \\
\hline $\mathrm{FEV}_{1}($ mean $\pm \mathrm{SD}), \mathrm{L}$ & $1.5 \pm 0.4$ & $1.2 \pm 0.5$ \\
\hline IVC (mean $\pm \mathrm{SD}), \mathrm{L}$ & $2.7 \pm 0.7$ & $2.8 \pm 0.5$ \\
\hline Tiffeneau index (mean \pm SD), \% & $55 \pm 13$ & $44 \pm 15$ \\
\hline $\mathrm{FEV}_{1}($ mean $\pm \mathrm{SD}), \%$ predicted & $43 \pm 12$ & $44 \pm 10$ \\
\hline Work load (mean $\pm \mathrm{SD}), \mathrm{W}$ & $54.9 \pm 22.4$ & $52.6 \pm 24.6$ \\
\hline$\dot{\mathrm{V}}_{\mathrm{O}_{2}}($ mean $\pm \mathrm{SD}), \mathrm{mL} / \mathrm{kg} / \mathrm{min}$ & $13.9 \pm 2.7$ & $13.9 \pm 3.0$ \\
\hline 6MWT (mean $\pm \mathrm{SD}), \mathrm{m}$ & $551 \pm 106$ & $574 \pm 98$ \\
\hline \multicolumn{3}{|l|}{ Total comorbidities, $n$} \\
\hline Hypertension & 7 & 8 \\
\hline Cardiovascular diseases & 2 & 4 \\
\hline Cancer & 1 & 3 \\
\hline Diabetes mellitus & 0 & 2 \\
\hline Other & 13 & 13 \\
\hline \multicolumn{3}{|l|}{$\begin{array}{l}\mathrm{BMI}=\text { body mass index } \\
\mathrm{IVC}=\text { inspiratory vital capacity } \\
\dot{\mathrm{V}}_{\mathrm{O}_{2}}=\text { oxygen uptake } \\
6 \mathrm{MWT}=6 \text {-min walk test }\end{array}$} \\
\hline
\end{tabular}

lung function in either group was observed at the beginning or end of the treatment period, suggesting that airway obstruction was a fixed determinant of exercise limitation.

\section{MWT}

Before training, subjects in the compressed air group walked $551 \pm 106 \mathrm{~m}$. After 12 weeks of training, they walked $621 \pm 76 \mathrm{~m}$. The 24 -week training mean distance amounted to $635 \pm 63 \mathrm{~m}$. Subjects in the oxygen group walked $574 \pm 98 \mathrm{~m}$ at baseline and improved to $630 \pm 88 \mathrm{~m}$ after 12 weeks and to $647 \pm 99 \mathrm{~m}$ after 24 weeks of training (Fig. 2). The differences between baseline and 12 weeks and between baseline and 24 weeks reached significance ( $P=.001$ for air supply, $P=.002$ for oxygen supply), whereas the difference between 12 and 24 weeks failed to reach significance in both groups $(P=.27)$.

\section{Spiroergometry}

For all subjects, the maximal work load increased from $52.6 \pm 24.6 \mathrm{~W}$ at baseline to $63.0 \pm 26.9 \mathrm{~W}$ after 12 weeks of training and remained nearly constant in the post-training period $(63.7 \pm 33.7 \mathrm{~W})$. The physiologic variables at maximal work load are shown in Table 4. Figures 3-5 illustrate the percentage change in maximal work load, peak ventilation, and peak $\dot{\mathrm{V}}_{\mathrm{O}_{2}}$. In the compressed air group,

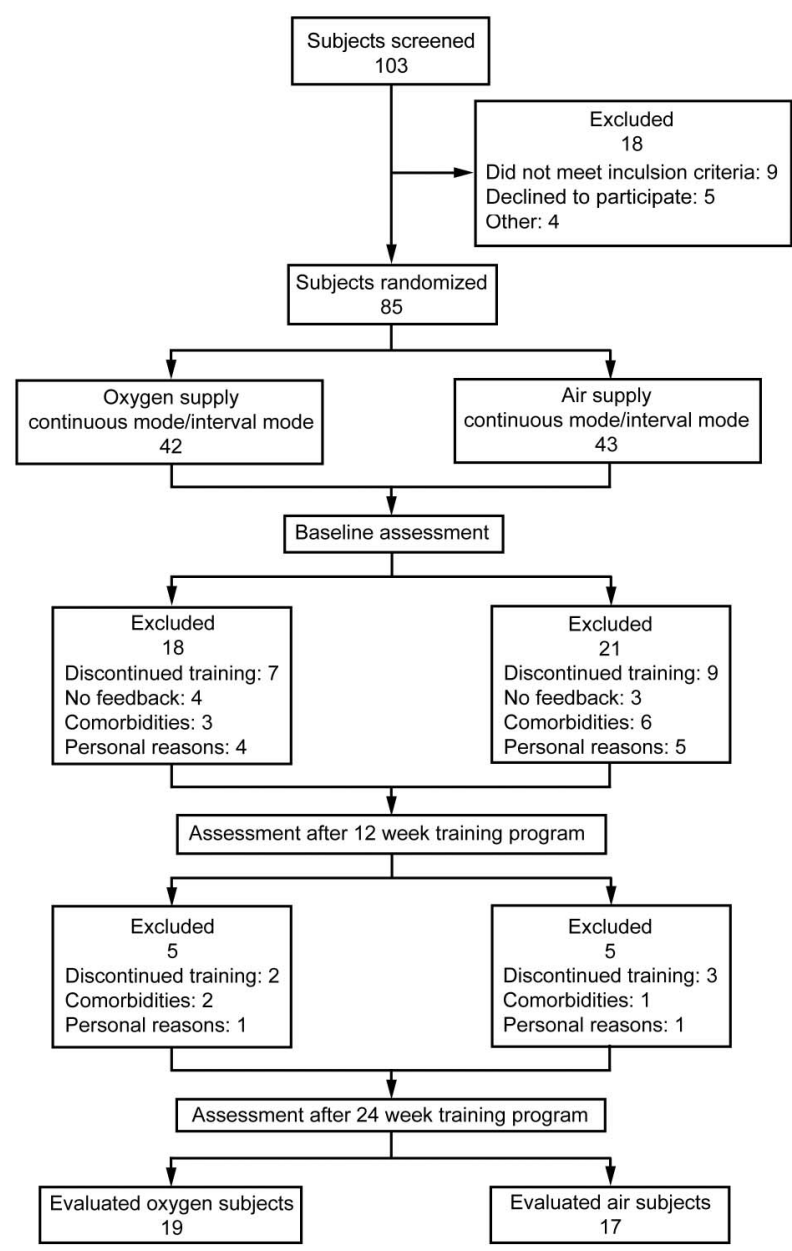

Fig. 1. Study flow chart.

the maximal work load increased from $54.6 \pm 22.4 \mathrm{~W}$ at baseline to $68.4 \pm 26.9 \mathrm{~W}$ after 12 weeks of training and remained nearly constant in the post-training period $(68.7 \pm 25.7 \mathrm{~W})$. However, there was no difference in the effect of training in comparison with the oxygen group.

Heart rate and lactic acid concentration tended to decline at submaximal work loads. The $35-\mathrm{W}$ stages may be taken as an example because they could be performed by all subjects, but no significance was observed.

All subjects tolerated the stepwise increases in training load well. With respect to the training mode, 10 subjects preferred continuous training, 16 subjects favored interval training, and 10 subjects were neutral.

\section{Quality of Life}

In all subgroups of SF-36, an increase in quality of life could be detected. The main effect occurred between baseline and 12 weeks, whereas the results at 12 and 24 weeks were similar. Except for the subgroups bodily pain, emotional role functioning, and physical role functioning, the 


\section{$\mathrm{O}_{2}$ Supply During Exercise Training in Subjects With COPD}

Table 3. Lung Function Data Before Training (Baseline) and After 12 and 24 Weeks

\begin{tabular}{|c|c|c|c|c|c|c|}
\hline \multirow{2}{*}{ Parameter } & \multicolumn{3}{|c|}{ Compressed Air Group $(n=17)$} & \multicolumn{3}{|c|}{ Oxygen Group $(n=19)$} \\
\hline & Baseline & $12 \mathrm{wk}$ & $24 \mathrm{wk}$ & Baseline & 12 wk & 24 wk \\
\hline IVC, L & $2.7 \pm 0.7$ & $2.9 \pm 0.9$ & $2.7 \pm 0.7$ & $2.8 \pm 0.8$ & $2.8 \pm 0.7$ & $2.7 \pm 0.7$ \\
\hline $\mathrm{FEV}_{1}, \mathrm{~L}$ & $1.5 \pm 0.4$ & $1.5 \pm 0.5$ & $1.5 \pm 0.5$ & $1.2 \pm 0.5$ & $1.3 \pm 0.5$ & $1.2 \pm 0.5$ \\
\hline Total $\mathrm{R}_{\mathrm{aw}}, \mathrm{cm} \mathrm{H}_{2} \mathrm{O} / \mathrm{L} / \mathrm{s}$ & $3.1 \pm 1.0$ & $3.1 \pm 2.0$ & $3.1 \pm 2.0$ & $4.1 \pm 2.0$ & $4.1 \pm 1.0$ & $3.1 \pm 2.0$ \\
\hline TLC, L & $6.7 \pm 1.4$ & $6.9 \pm 1.6$ & $6.6 \pm 1.5$ & $7.5 \pm 1.2$ & $7.0 \pm 1.2$ & $7.3 \pm 1.2$ \\
\hline $\mathrm{RV}, \mathrm{L}$ & $3.8 \pm 1.0$ & $3.8 \pm 1.2$ & $3.8 \pm 1.2$ & $4.6 \pm 1.5$ & $4.1 \pm 1.0$ & $4.5 \pm 0.9$ \\
\hline RV/TLC, $\%$ predicted & $150 \pm 26$ & $145 \pm 30$ & $149 \pm 27$ & $161 \pm 25$ & $149 \pm 19$ & $159 \pm 27$ \\
\hline $\begin{array}{l}\text { Data are mean } \pm \text { SD. } \\
\text { IVC }=\text { inspiratory vital capacity } \\
\mathrm{R}_{\mathrm{aw}}=\text { airway resistance } \\
\mathrm{TLC}=\text { total lung capacity } \\
\mathrm{RV}=\text { residual volume }\end{array}$ & & & & & & \\
\hline
\end{tabular}

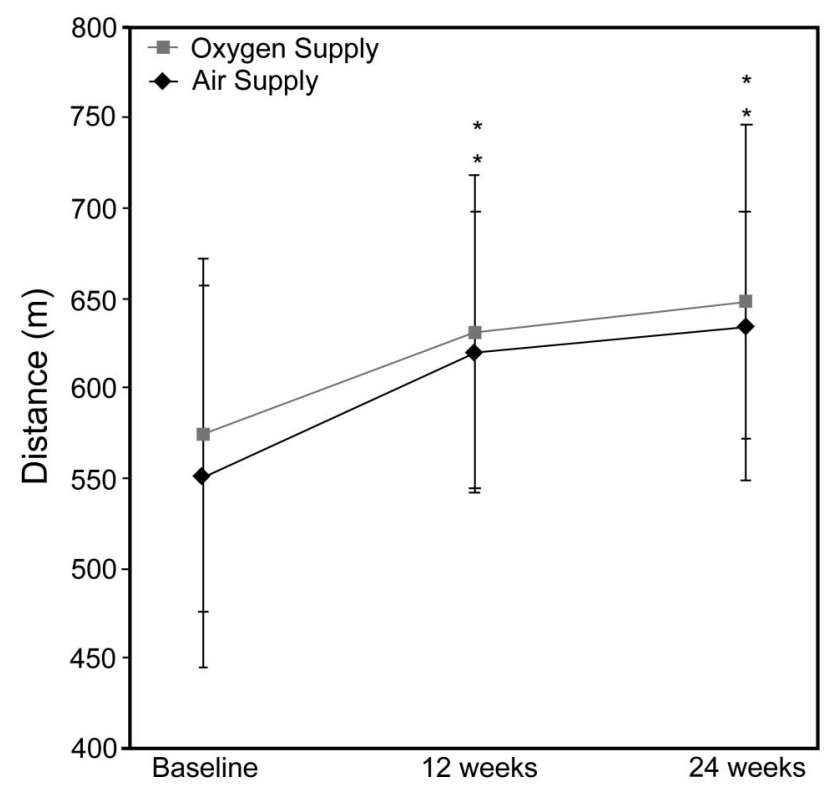

Fig. 2. The 6-min walk distance before (baseline) and after 12 and 24 weeks of training. Data are shown as mean \pm SD. * Significant difference from baseline.

differences between baseline and 24 weeks and between baseline and 12 weeks ( 2 exceptions) were statistically significant (Figs. 6 and 7).

\section{Discussion}

We investigated the effects of a 24-week structured training program on normoxemic COPD subjects with or without oxygen supplementation throughout the training sessions. Three major findings resulted from this study. First, endurance training 3 times/week resulted in significant improvements in quality of life and exercise capacity in subjects with moderate-to-severe COPD within the first 12 weeks. Second, these effects remained stable over the following 12 weeks. Third, supplemental oxygen during the training program did not result in additional benefits in this COPD subgroup (without considering long-term oxygen therapy).

The potential benefit of oxygen supplementation during exercise is still a matter of debate, and hyperoxia has no clear effect on the results of exercise training in COPD subjects with or without documented desaturation during exercise. ${ }^{16}$ A 1984 study showed promising effects of oxygen supplementation during physical rehabilitation on both inspiratory and leg muscles. ${ }^{17}$ Unfortunately, the training prescription was relatively weak, and moreover, the investigation did not include a control group. Another study conducted a 7-week training trial in normoxemic subjects. Although the peak performance during incremental exercise testing did not significantly differ between groups, the authors found larger improvements in constant work time in the oxygen group compared with the air control group. ${ }^{10}$

In our own double-blinded controlled pretest study, ${ }^{9}$ we used $40 \%$ oxygen during exercise training via full-face mask and identified a higher possible work load during cycle training in comparison with the room air group after 12 weeks. The higher work load during exercise training in the oxygen group led to better results in the final tests. The change in oxygen application from a mask to a cannula may explain the different results compared with the baseline test situation. However, additional and also randomized controlled trials could not confirm the benefits. ${ }^{18,19}$ Previous studies showed no additional beneficial effects in COPD subjects who participated in pulmonary rehabilitation and experienced desaturation without severe resting hypoxemia. ${ }^{20,21}$ One explanation for the discrepancy may be the subjective and symptom-related control in training intensity progress (ie, subjects' dyspnea and fatigue) that has been used in most studies. To obtain identical relative loads in our subgroups, we fixed both the initial training 


\section{$\mathrm{O}_{2}$ Supply During Exercise Training in Subjects With COPD}

Table 4. Peak Values During Spiroergometry and 6MWT Before Training (Baseline) and After 12 and 24 Weeks

\begin{tabular}{|c|c|c|c|c|c|c|c|c|c|c|}
\hline \multirow{2}{*}{ Parameter } & \multicolumn{5}{|c|}{ Compressed Air Group $(n=17)$} & \multicolumn{5}{|c|}{ Oxygen Group $(n=19)$} \\
\hline & Baseline & $12 \mathrm{wk}$ & $P$ & 24 wk & $P$ & Baseline & $12 \mathrm{wk}$ & $P$ & $24 \mathrm{wk}$ & $P$ \\
\hline Ventilation, L/min & $34.8 \pm 7.4$ & $37.3 \pm 10.8$ & & $37.9 \pm 11.8$ & & $35.1 \pm 9.9$ & $37.5 \pm 11.8$ & & $36.8 \pm 14.3$ & \\
\hline$\dot{\mathrm{V}}_{\mathrm{O}_{2}}, \mathrm{~mL} / \mathrm{kg} / \mathrm{min}$ & $13.9 \pm 2.7$ & $14.8 \pm 3.5^{*}$ & .15 & $14.7 \pm 4.1$ & .71 & $13.9 \pm 3.0$ & $15.3 \pm 3.4$ & .005 & $15.5 \pm 4.2$ & .08 \\
\hline Work load, W & $54.9 \pm 22.4$ & $68.4 \pm 26.9$ & .001 & $68.7 \pm 25.7$ & .004 & $52.6 \pm 24.6$ & $63.0 \pm 26.9$ & $<.001$ & $63.7 \pm 33.7$ & .005 \\
\hline Lactic acid, mmol/L & $3.2 \pm 0.72$ & $3.1 \pm 0.74$ & & $2.7 \pm 0.82$ & & $3.3 \pm 0.93$ & $2.9 \pm 0.93$ & & $3.0 \pm 0.89$ & \\
\hline $\begin{array}{l}\text { Heart rate at } 35-\mathrm{W} \\
\text { stage, beats } / \mathrm{min}\end{array}$ & $104 \pm 17$ & $95 \pm 13$ & & $96 \pm 11$ & & $108 \pm 18$ & $109 \pm 20$ & & $105 \pm 18$ & \\
\hline 6MWD, m & $551 \pm 106$ & $621 \pm 76$ & $<.001$ & $635 \pm 63$ & $<.001$ & $574 \pm 98$ & $630 \pm 88$ & .002 & $647 \pm 99$ & .001 \\
\hline $\begin{array}{l}\text { Data are mean } \pm \mathrm{SD} . \\
6 \mathrm{MWT}=6 \text {-min walk test } \\
\dot{\mathrm{V}}_{\mathrm{O}_{2}}=\text { oxygen uptake } \\
6 \mathrm{MWD}=6 \text {-min walk distar }\end{array}$ & & & & & & & & & & \\
\hline
\end{tabular}

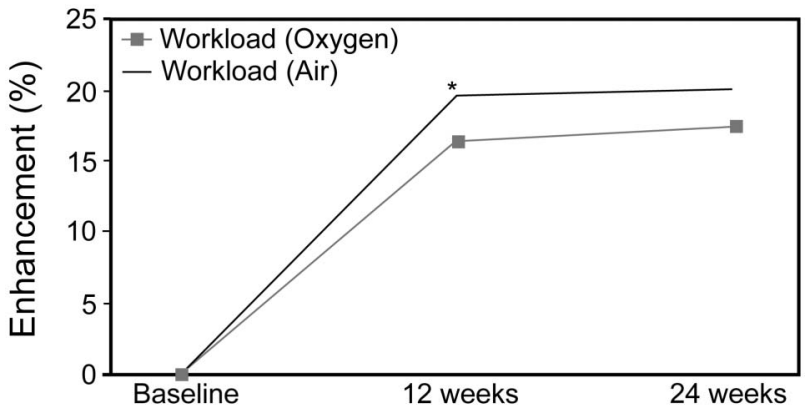

Fig. 3. Percent changes in peak work load after 12 and 24 weeks of training. * Significant difference from baseline. $P=.03$ (oxygen) and .03 (air).

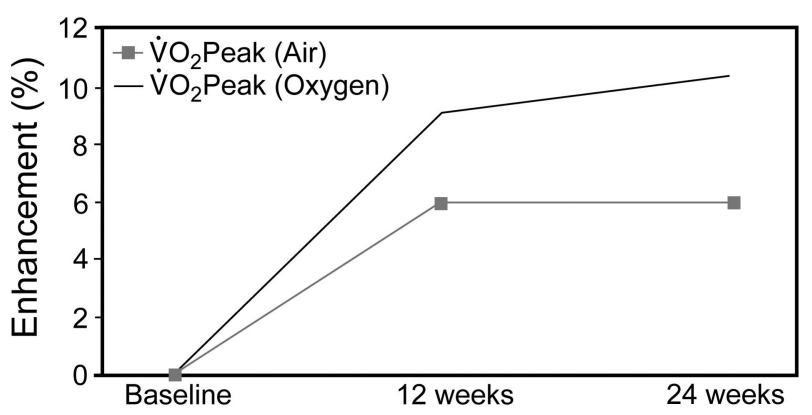

Fig. 4. Percent change in peak oxygen uptake $\left(\dot{\mathrm{V}}_{\mathrm{O}_{2}}\right)$ after 12 and 24 weeks of training. $P=.02$ (oxygen) and .049 (air).

loads and the progressive increase in work load a priori. However, we also could not find any effect of oxygen supplementation on peak performance or submaximal loads (6MWT) or quality of life.

One finding of this study is a ceiling effect of training adaptation in COPD despite a progressive increase in training intensity. After 12 weeks of training, we measured an increase of $\sim 22 \%$ in peak performance during cycling and an $11 \%$ extension of distance covered during the 6MWT. Surprisingly, although the training loads for the next

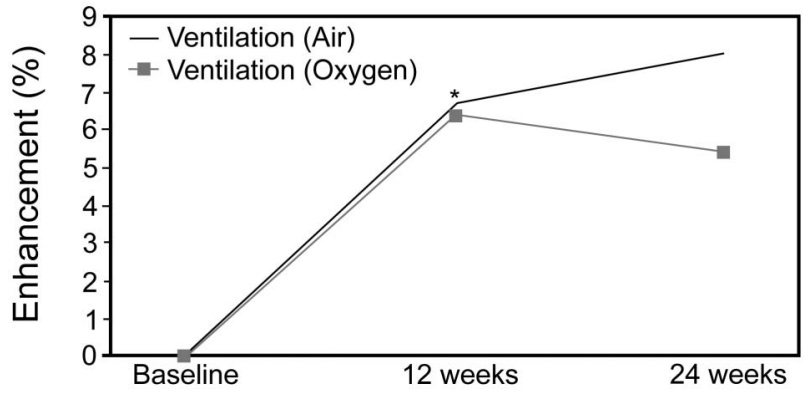

Fig. 5. Percent change in peak ventilation after 12 and 24 weeks of training. * Significant difference from baseline. $P=.04$ (oxygen) and .04 (air).

12 weeks adjusted to the mid-investigation peak performances and the progression of intensity was identical to the initial period, we could not detect any further increase in peak performance and only a non-significant improvement in walking distance (2.4\%).

Moreover, peak $\dot{\mathrm{V}}_{\mathrm{O}_{2}}$ showed a ceiling effect, and quality-of-life parameters did not differ significantly between 12 and 24 weeks. This phenomenon occurred independently of the training mode in the second period (ie, continuous or interval exercises). This is similar to the findings of another trial in which the authors showed that interval training was associated with a lower intensity of dyspnea during exercise and fewer unintended breaks, achieving similar improvements in exercise capacity compared with continuous training in pre-lung transplant subjects with COPD. ${ }^{22}$ However, with respect to training adherence, both forms should be offered to patients, and the choice should be made by the patients themselves.

Although several studies showed a seasonal impact on hospital visits of subjects with COPD, with a peak during winter, ${ }^{23-25}$ as a cause of the actual ceiling effect, a systematic seasonal influence cannot be assessed. Our study was conducted throughout the year, so baseline, 12-week, 


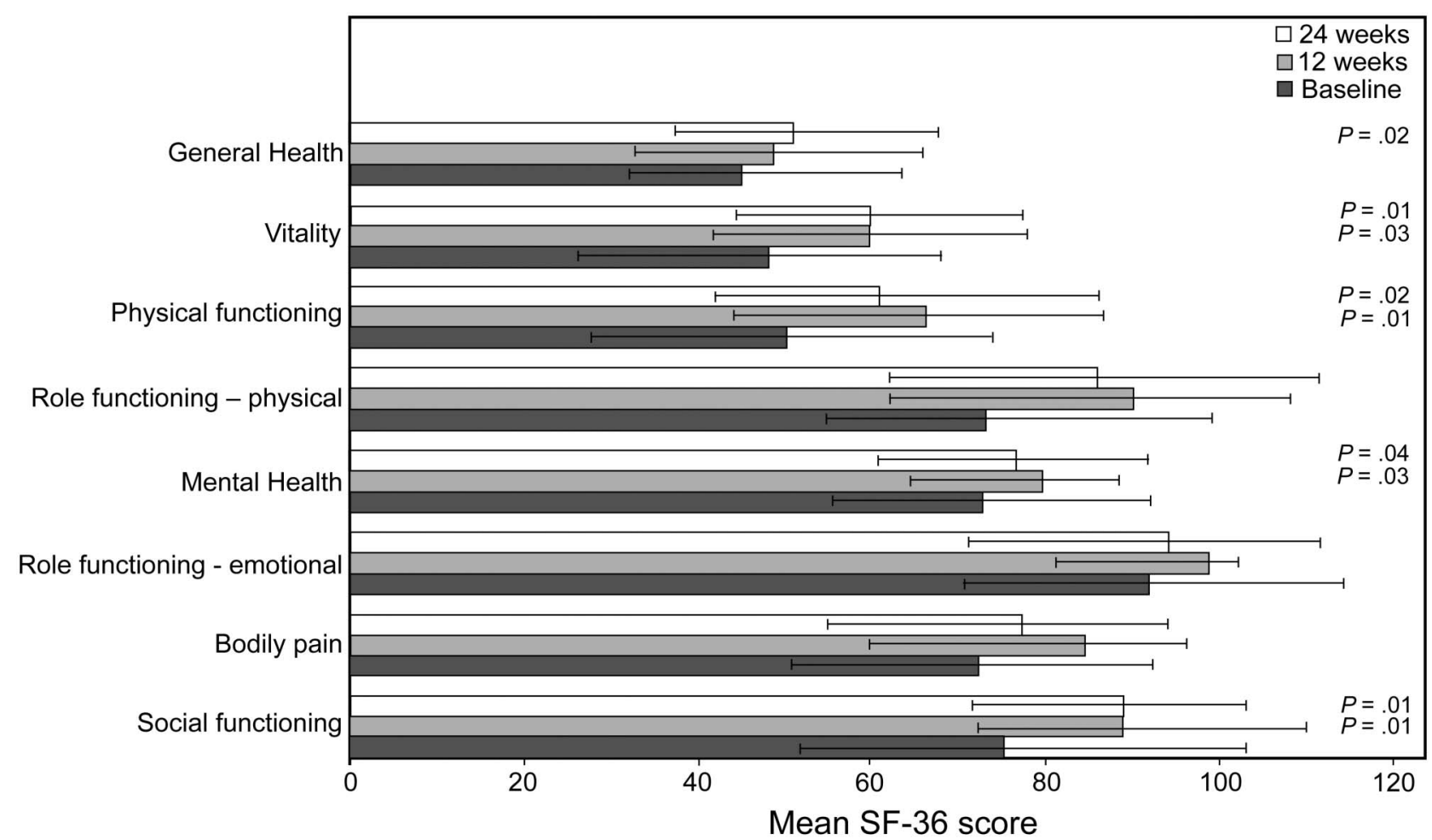

Fig. 6. Medical Outcomes Study 36-Item Short Form questionnaire (SF-36) scores of the oxygen group before (baseline) and after 12 and 24 weeks of training. Data are shown as mean \pm SD.

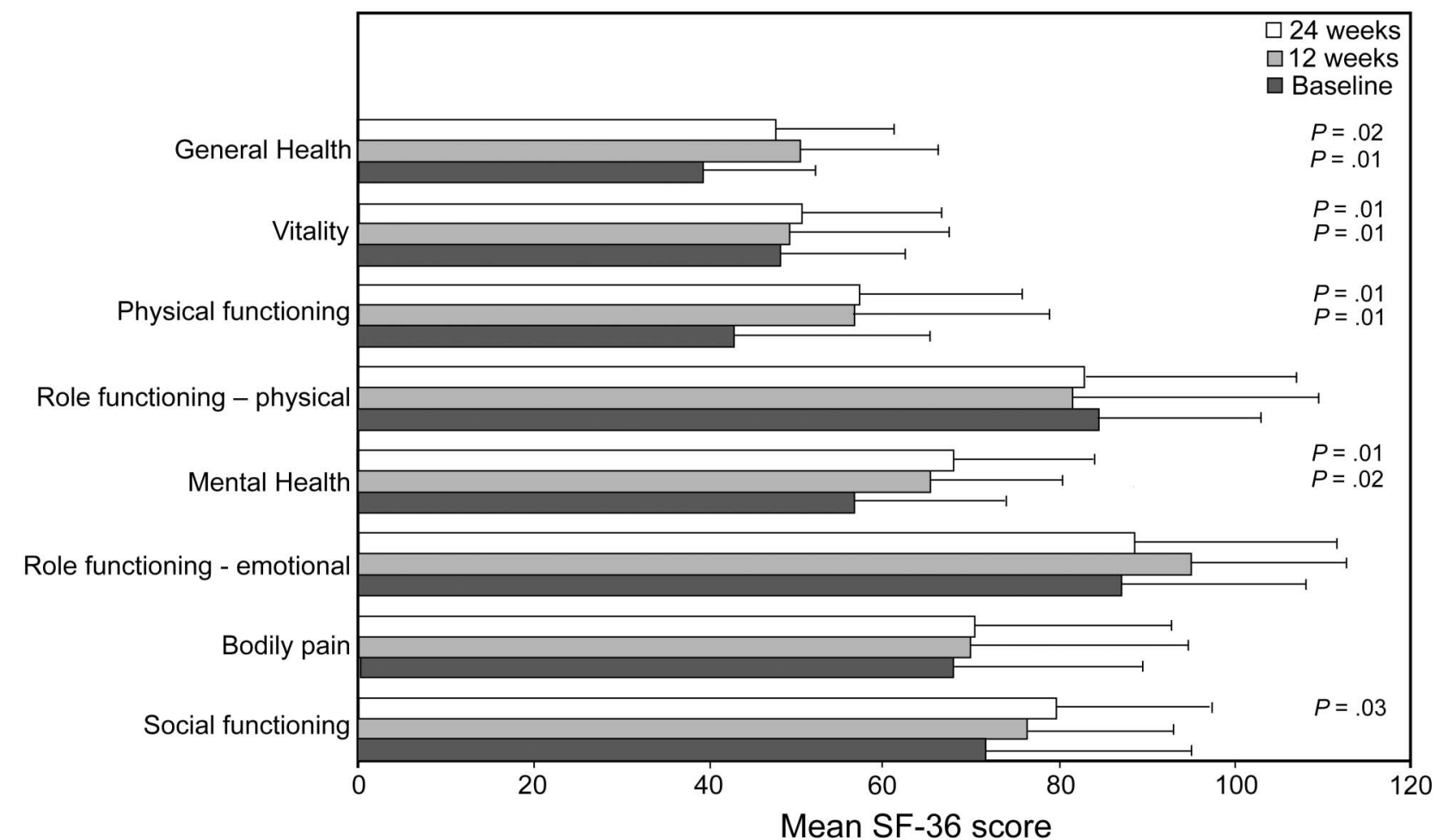

Fig. 7. Medical Outcomes Study 36-Item Short Form questionnaire (SF-36) scores of the compressed air group before (baseline) and after 12 and 24 weeks of training. Data are shown as mean \pm SD. 


\section{$\mathrm{O}_{2}$ Supply During Exercise Training in Subjects With COPD}

and 24-week evaluations did not follow a uniform seasonal pattern. Also, a simple learning effect (ie, higher utilization of existing performance capacity within the first half of the training period) appears unlikely. At baseline and 12 and 24 weeks, mean lactate concentrations at the end of exercise were nearly identical. The peak lactate concentration of $\sim 4 \mathrm{mmol}$ in all tests indicates that the subjects with COPD ceased exercise when the lactate concentration exceeded maximal steady states (ie, at the ventilatory threshold).

It has to be taken into consideration that our subjects performed endurance training exclusively using large muscle groups. In comparable studies of 7 -week duration, ${ }^{10,18,26}$ peak work load also significantly increased (range of $12-24 \%$, mean of $18.4 \%$ ), with improvement in peak $\dot{\mathrm{V}}_{\mathrm{O}_{2}}$ of only a small and mainly insignificant amount $(0-6 \%$, mean of $3.4 \%)$. This indicates an enhanced mechanical efficiency (work per unit oxygen), which is supported by the fact that enhanced mechanical efficiency in untrained subjects with COPD is much lower than that in healthy subjects matched for age and activity level. ${ }^{4}$ Our results may be explained by a completed gain in enhanced mechanical efficiency within the initial 12 weeks and a ventilation limitation that inhibits further progress in aerobic metabolism at least during training with large muscle groups.

Our study had some limitations. First, there was a relatively high dropout rate (49 of 85 subjects) during the study period, which is probably due to the long study period, the high level of training intensity, and the selected COPD subgroup, which showed exercise intolerance as described above in detail. Results of epidemiologic studies have shown that COPD is frequently associated with comorbidities, the most serious and prevalent being cardiovascular disease, lung cancer, osteoporosis, muscle weakness, and cachexia, as also seen in this study population. This might be the reason for the dropout rate. However, it has occasionally been observed in such settings. ${ }^{27}$ Furthermore, our results cannot be applied directly to different training forms, such as strength training or endurance training with small muscle groups. Additional studies focusing on long-term effects of these alternative training programs should be performed.

\section{Conclusions}

Cycle training increases exercise performance and quality of life to comparable amounts after 12 weeks of structured physical training. Whatever factors contribute to improved exercise performance in subjects with COPD, it seems that they reach ceiling effects after 12 weeks when endurance training is performed with large muscle groups, with no further enhancement during the following 12 weeks and with no influence of oxygen supplementation during exercise.

\section{REFERENCES}

1. Stridsman C, Lindberg A, Skär L. Fatigue in chronic obstructive pulmonary disease: a qualitative study of people's experiences. Scand J Caring Sci 2014;28(1):130-138.

2. Wagner PD. Skeletal muscles in chronic obstructive pulmonary disease: deconditioning or myopathy? Respirology 2006;11(6):681-686.

3. Eid AA, Ionescu AA, Nixon LS, Lewis-Jenkins V, Matthews SB, Griffiths TL, Shale DJ. Inflammatory response and body composition in chronic obstructive pulmonary disease. Am J Respir Crit Care Med 2001;164(8 Pt 1):1414-1418.

4. Decramer M, Lacquet LM, Fagard R, Rogiers P. Corticosteroids contribute to muscle weakness in chronic airflow obstruction. Am J Respir Crit Care Med 1994;150(1):11-16.

5. Chin RC, Guenette JA, Cheng S, Raghavan N, Amornputtisathaporn $\mathrm{N}$, Cortés-Télles A et al. Does the respiratory system limit exercise in mild COPD? Am J Respir Crit Care Med 2013;187(12):13151323.

6. Spruit MA, Singh SJ, Garvey C, ZuWallack R, Nici L, Rochester C, et al. An official American Thoracic Society/European Respiratory Society statement: key concepts and advances in pulmonary rehabilitation. Am J Respir Crit Care Med 2013;188(8):e13-e64.

7. Global Initiative for Chronic Obstructive Lung Disease. Global strategy for the diagnosis, management, and prevention of chronic obstructive pulmonary disease. Updated 2014. http://www.goldcopd. com/uploads/users/files/GOLD_Report_2014_Oct30.pdf. Accessed May 27, 2014.

8. Beauchamp MK, Nonoyama M, Goldstein RS, Hill K, Dolmage TE, Mathur S, Brooks D. Interval versus continuous training in individuals with chronic obstructive pulmonary disease-a systematic review. Thorax 2010;65(2):157-164.

9. Spielmanns M, Baum K, Hoffmann U. Effekte eines 12-wöchigen Trainings bei nicht hypoxischen COPD-Patienten unter Sauerstoffsupplementierung. Pneumologie 2009;63(Suppl 3):S3. Article in German.

10. Emtner M, Porszasz J, Burns M, Somfay A, Casaburi R. Benefits of supplemental oxygen in exercise training in nonhypoxemic chronic obstructive pulmonary disease patients. Am J Respir Crit Care Med 2003;168(9):1034-1042.

11. ATS Committee on Proficiency Standards for Clinical Pulmonary Function Laboratories. ATS statement: guidelines for the six-minute walk test. Am J Respir Crit Care Med 2002;166(1):111-117.

12. Wasserman K, Hansen JE, Sue DY, Casaburi R, Whipp BJ. Principles of exercise testing and interpretation including pathophysiology and clinical application, 3rd edition. Philadelphia: Lippincott Williams \& Wilkins; 1999:199.pxv.

13. Baldari C, Bonavolontà V, Emerenziani GP, Gallotta MC, Silva AJ, Guidetti L. Accuracy, reliability, linearity of Accutrend and Lactate Pro versus EBIO Plus analyser. Eur J Appl Physiol 2009;107(1): 105-111.

14. Kindermann W. Anaerobe Schwelle. Dtsch Z Sportmed 2004;55(3): 161-162. Article in German.

15. Tarlov AR, Ware JE Jr, Greenfield S, Nelson EC, Perrin E, Zubkoff M. The Medical Outcomes Study: an application of methods for monitoring the results of medical care. JAMA 1989;262(7):925-930.

16. Wijkstra PJ, Wempe JB. New tools in pulmonary rehabilitation. Eur Respir J 2011;38(6):1468-1474.

17. Zack MB, Palange AV, Drews PG, Stehm D. Ventilatory and nonventilatory muscle exercise in COPD rehabilitation. Respir Ther 1984; 14(5):41-45. 


\section{$\mathrm{O}_{2}$ Supply During Exercise Training in Subjects With COPD}

18. Rooyackers JM, Dekhuijzen PN, Van Herwaarden CL, Folgering HT. Training with supplemental oxygen in patients with COPD and hypoxaemia at peak exercise. Eur Respir J 1997;10(6):12781284.

19. Garrod R, Paul EA, Wedzicha JA. Supplemental oxygen during pulmonary rehabilitation in patients with COPD with exercise hypoxemia. Thorax 2000;55(7):539-543.

20. Moore RP, Berlowitz DJ, Denehy L, Pretto JJ, Brazzale DJ, Sharpe $\mathrm{K}$, et al. A randomised trial of domiciliary, ambulatory oxygen in patients with COPD and dyspnoea but without resting hypoxaemia. Thorax 2011;66(1):32-37.

21. Ringbaek T, Martinez G, Lange P. The long-term effect of ambulatory oxygen in normoxaemic COPD patients: a randomised study. Chron Respir Dis 2013;10(2):77-84.

22. Gloeckl R, Halle M, Kenn K. Interval versus continuous training in lung transplant candidates: a randomized trial. J Heart Lung Transplant 2012;31(9):934-141.
23. Weiss KB. Seasonal trends in US hospitalizations and mortality. JAMA 1990;263(17):2323-2328.

24. Reichert TA, Simonsen L, Sharma A, Pardo SA, Fedson DS, Miller MA. Influenza and the winter increase in mortality in the United States, 1959-1999. Am J Epidemiol 2004;160(5):492-502.

25. Yap FH, Ho PL, Lam KF, Chan PK, Cheng YH, Peiris JS. Excess hospital admissions for pneumonia, chronic obstructive pulmonary disease, and heart failure during influenza seasons in Hong Kong. J Med Virol 2004;73(4):617-623.

26. Baumann HJ, Kluge S, Rummel K, Klose H, Hennigs JK, Schmoller T, Meyer A. Low intensity, long-term outpatient rehabilitation in COPD: a randomised controlled trial. Respir Res. 2012; 13:86.

27. Greulich T, Kehr K, Nell C, Koepke J, Haid D, Koehler U, et al. A randomized clinical trial to assess the influence of 3 months training program (gym-based individualized vs. calisthenics-based nonindividualized) in COPD-patients. Respir Res 2014;15:36. 